\title{
Violencia y delincuencia en México: el uso político del miedo* \\ Violence and crime in Mexico: The political use of fear
}

\author{
Araceli Mendieta Ramírez \\ Universidad Autónoma del Estado de México \\ ORCID ID 0000-0002-4507-237X \\ mendieta.araceli@gmail.com
}
Cita recomendada:
Mendieta, A. (2019). Violencia y delincuencia en México: el uso político del miedo. Eunomía. Revista en Cultura de la Legalidad, 17, 182-206.
doi: https://doi.org/10.20318/eunomia.2019.5011

Recibido / received: 01/03/2018

Aceptado / accepted: 10/05/2019

\begin{abstract}
Resumen
Se trata de una discusión sobre la pluralidad de las violencias, entendidas como una construcción cultural. Nos referimos principalmente a dos dimensiones de la violencia: directa y estructural. La primera dimensión suele ser la más notoria, porque implica la acción intencionada de daño entre dos o más sujetos, mientras la segunda es más silenciosa e invisible, porque ha sido normalizada y preservada en los sistemas económicos, políticos y culturales, como en el caso de la desigualdad con efectos en las desventajas heredadas de ciertos sectores de la población. Ambas, dimensiones, suelen tratarse de forma independiente, pero son indisolubles, se entrecruzan y generan una pluralidad de formas y efectos que las políticas públicas no han logrado mitigar; en consecuencia, la degradación social es progresiva en los territorios. En México, la violencia directa y su manifestación en la delincuencia, ha sido una justificación para el uso político del miedo, a fin de imponer agendas políticas, persuadir a los ciudadanos y legitimar acciones de seguridad; todo ello, sin lograr resarcir las manifestaciones de las violencias, ni la delincuencia.
\end{abstract}

Palabras clave

Violencia estructural, violencia directa, miedo, territorio, prevención.

\footnotetext{
* El presente artículo consiste en una reflexión sobre la fusión de las violencias en el territorio desde la antropología de la violencia, a partir de la recuperación de información de otros autores especialistas en el tema y fuentes que han documentado casos de violencia directa en diversas partes de México.
} 


\begin{abstract}
It is a discussion about the plurality of violence, understood as a cultural construct. We are mainly talking about two dimensions of violence: direct and structural. The first dimension is usually the most notorious, because it implies the intentional action of harm between two or more subjects, while the second is more silent and invisible, because it has been standardized and preserved in economic, political and cultural systems, as in the case of inequality with effects on the inherited disadvantages of certain sections of the population. Both dimensions are usually treated independently, but are indissoluble, intersect and generate a plurality of forms and effects that public policies have failed to mitigate; consequently, social degradation is progressive in the territories. In Mexico, direct violence and its manifestation in crime has been a justification for the political use of fear, in order to impose political agendas, persuade citizens and legitimize security actions; all this, without being able to compensate the manifestations of the violence, not the delinquency.
\end{abstract}

\title{
Keywords
}

Structural violence, direct violence, fear, territory, prevention.

\begin{abstract}
SUMARIO. 1. Introducción. 2. La reproducción e institucionalización de la violencia. 3. Violencia y territorio. 4 La violencia invisibilizada, normalizada y justificada. 5. El miedo colectivo y sus usos políticos. 6 . La panacea de la violencia de estado. 7. ¿Prevención o precaución del delito? 8. Conclusiones.
\end{abstract}

\section{Introducción}

En la actualidad, la violencia es parte de las preocupaciones de las Ciencias Sociales, las características de la violencia en cada territorio han despertado viejos debates y han abierto nuevas polémicas y enfoques. Uno de los debates de interés para estas líneas es justamente la pluralidad de las violencias (Arendth, 2008; Gledhill, 2016), por ejemplo, la violencia directa que es estimada regularmente en las estadísticas delincuenciales y la violencia estructural, manifiesta en las profundas brechas de desigualdad socioterritorial.

La violencia puede definirse como la acción dirigida e intencionada de dañar a otra u otras personas (Arendth, 2008); algunos especialistas han realizado complejas categorías sobre la violencia, pero para esta discusión sólo nos referimos a la violencia directa y la violencia estructural. Ya el famoso antropólogo británico John Gledhill (2016) ha planteado que la única separación posible es la abstracta, porque en la realidad están totalmente fusionadas. Mientras la violencia directa es más tangible, la violencia estructural es más difícil de reconocer porque ha sido institucionalizada, en los sistemas económicos, políticos, sociales y culturales, para mantener el poder de las élites sobre la población.

En México, ambas dimensiones de la violencia son graves; sin embargo, comúnmente se tratan por separado. Mientras la violencia directa se mide en los territorios en función de los índices delincuenciales, a partir de los delitos denunciados, la presencia de crimen organizado o narcotráfico. La violencia estructural es normalizada y justificada en las brechas de desigualdad socioterritorial y corresponde al orden de las políticas sociales. 
En ambas dimensiones sigue habiendo un lado oscuro; con respecto a los índices delincuenciales, quedan fuera de las mediciones todos aquellos delitos que no son denunciados, ya sea por la falta de capacidades de los sistemas de seguridad y de justicia, por corrupción o porque existen formas de violencia directa que no son identificadas como delito y no son incluidas dentro de las estadísticas, por ejemplo: el acoso sexual y emocional, ataque verbal, violencia psicológica y simbólica o negligencia, entre otros, que llegan a provocar severos daños.

La violencia estructural es más silenciosa e invisible porque es violencia cotidiana que hemos normalizado, pero se caracteriza por reproducir diferencias de poder como en el racismo, clasismo, desigualdad de género, entre otras, como parte del modus vivendi. No obstante, ignorar esta dimensión de la violencia implica que se mantiene y amalgama con otras violencias, y progresivamente se intensifica al mismo tiempo que la violencia directa, de tal forma que, las medidas enfocadas a resarcir sus manifestaciones, como: las políticas públicas, el endurecimiento de las penas y la militarización del país; no logran disminuir los riesgos en los territorios.

En este orden de ideas, el presente documento tiene la finalidad de mostrar como ambas dimensiones de la violencia se fusionan, entrecruzan, perpetúan e intensifican; simultáneamente, el tejido social se fragmenta en los territorios con altos índices de delincuencia, por la incertidumbre, el miedo y la desconfianza. Ante la espacialización de la violencia, los gobiernos han realizado un uso político de las emociones como dispositivo de control para mantener sus círculos de poder y como medida disciplinaria ante sus detractores.

\section{La reproducción e institucionalización de la violencia}

Es un hecho que la violencia ha acompañado los procesos históricos de diferentes culturas, y que en cada lugar y tiempo la apreciación de las acciones violentas ha sido distinta; mientras culturas como la de los griegos llegaron a glorificar las acciones violentas por considerarlas una manifestación de la fuerza física (Arendt, 2008, pp. 96-101), en las culturas contemporáneas, la violencia ha llegado a ser un indicador de la crisis social y moral (López, Kessler, Urresti et al, 2008, p. 135) en los territorios.

A pesar de la larga trayectoria de la violencia en las sociedades, es necesario precisar que no es inherente a la naturaleza del hombre, pero quizá sí es inherente a la naturaleza de la sociedad, debido a que es instrumental y cada sociedad ha creado herramientas para potenciarla e intensificarla (Arendt, 2008, pp. 63, 70-73, 107).

En términos de la renombrada filosofa política Hannah Arendt, la violencia ha sido utilizada para mantener el poder, pero debe distinguirse porque es capaz de destruir al poder; textualmente explica: «la violencia aparece donde el poder está en peligro pero, confiada a su propio impulso, acaba por desaparecer el poder (Arendt, 2008, p. 77)». En esta perspectiva, la violencia es una manifestación del poder y su uso alcanza a regímenes políticos, grupos, organizaciones (sindicales, criminales), redes de narcotráfico, entre otros.

El empleo de la violencia por parte del estado, ha sido reconocido por Max Weber (1919) como un tipo de violencia legítima y posee sus propios instrumentos, como: la militarización del país, el sistema penitenciario, la maquinaria judicial, la tortura, la desaparición forzada, entre otros. Gledhill ha planteado todo un análisis de la violencia pública y privada en México y Brasil, la primera tiene que ver con esa violencia del Estado. 
Para Arendt, la violencia es instrumental, culturalmente aprendida, reproducida e institucionalizada y se distingue por la intención de provocar daño (Arendt, 2008). A menudo la violencia es confundida con la agresividad, pero son de naturaleza distinta, la agresión es parte de los instintos, inherente a la naturaleza humana (Baños, 2005) y la violencia es cultural, está marcada por la intencionalidad, se aprende, se permite y se reproduce en sociedad, incluso se intensifica o potencia colectivamente, aunque se exprese individualmente (Arendt, 2008).

Desde la antropología física, Agustín Axel Baños Nocedal, contribuye a clarificar la diferencia entre violencia y agresividad, mientras la agresividad «es una característica comportamental adaptativa presente en todas o casi todas las especies animales» (Baños, 2005, p. 42), forma parte del instinto de conservación y no hay una intención de dañar, la violencia es aprendida e implica la intención de daño. En la perspectiva de Baños, cuando una persona es atacada y reacciona defendiéndose o huyendo, lo que opera es su agresividad, mientras que en el atacante es la violencia (Baños, 2005).

Algunos especialistas en el estudio de la violencia en diversas disciplinas de las ciencias sociales, como Baños (2005), Feixa y Fernández (2004), Gledhill (2010, 2016) Recasens (2005-2006) y Tortosa (2008), coinciden en que la violencia permitida, justificada, normalizada e invisibilizada, favorece la reproducción, persistencia e intensidad de la violencia, y al mismo tiempo, la vulnerabilidad y sometimiento de los oprimidos.

La pluralidad de las violencias ha llevado a una diversidad de clasificaciones, entre las que podemos mencionar las de Andrés Recasens Salvo, quien identifica cuatro esferas: política (administrada por las autoridades), estructural (institucional, sistémica), simbólica (existe una legitimación de la desigualdad) y cotidiana («pequeñas brutalidades») (Recasens, 2005-2006); de acuerdo al nivel en que se presenta, puede ser: familia, escuela, comunidad (o barrio), ciudad, país o región (Tortosa, 2008).

La pluralidad de las violencias y de las apreciaciones sobre la violencia, hace necesario establecer un punto de partida. Para el caso del presente análisis, iniciaremos distinguiendo entre dos dimensiones fundamentales (Bufacchi, 2015; Gledhill, 2016): la violencia directa y la violencia estructural. Se trata de una separación abstracta, únicamente a nivel conceptual porque que en la realidad están mutuamente influenciadas, además de que dentro de cada dimensión podríamos continuar haciendo categorías.

La dimensión estructural de la violencia, «tiene que ver con la "maquinaria de opresión" engastada en los órdenes sociales, lo que incluye el racismo y la desigualdad de género» (Farmer et al, 2004, p. 307 citado en Gledhill, 2016, p. 13), y se refiere a la construcción de la violencia dentro de una estructura y se distingue por una desigualdad de poder y de oportunidades entre las élites y los oprimidos.

Arendt (2008) plantea que la violencia se ha institucionalizado y de esta manera se reproduce y se perpetúa en la sociedad y esto ha sido por medio de la violencia estructural. En esta misma dimensión, Vittorio Bufacchi identifica la violencia estructural o institucional, como «...más mortal y destructiva que la violencia directa» (Bufacchi, 2015, p. 22), porque tiene efectos en la desigualdad de poder y de oportunidades para los miembros de una sociedad.

La desigualdad es el ejemplo más claro de violencia estructural, porque la población afectada acumula desventajas de generación, en generación. La 
desigualdad tiene múltiples manifestaciones y entre estas, esta la desigualdad socioterritorial, donde puede verse territorios ganadores y perdedores, es decir, entre los territorios que han logrado beneficiarse de los sistemas, económico y político, imperantes y aquellos que se han mantenido excluidos del llamado «desarrollo nacional».

Con respecto a la dimensión de la violencia directa, se refiere a la violencia ejercida contra una persona o personas (Bufacchi, 2015, p. 22). En esta dimensión podríamos agregar una serie de categorías como la violencia juvenil, de género, sexual, étnica, intrafamiliar, terrorista, corporal y psíquica.

Una perspectiva muy interesante es la de John Gledhill, quien considera que existe una influencia bidireccional entre ambas dimensiones de la violencia y verlas por separado, como si existieran aisladas sólo nos conduce a perspectivas fragmentadas e incompletas de la violencia y oscurece su análisis. Para el caso de esta refkexión, la preocupación por la violencia estructural y directa, es el hilo conductor para abordar tres escenarios relacionados: la violencia invisibilizada (que imposibilita el reconocimiento de las víctimas y el acceso a la justicia), el uso político del miedo y la intensidad de la violencia.

\section{Violencia y territorio}

El análisis de la relación entre violencia y territorio es obligado, porque la dimensión sociogeográfica es el espacio donde converge la construcción material y simbólica de los pueblos; pero, también es el locus donde se amalgama la violencia estructural y la violencia directa. Algunos investigadores ya han planteado la importancia de hablar de la espacialización de la violencia o la geografía del miedo, como Fabián González Luna, quién identifica en el espacio o territorio «... un instrumento analítico estratégico para vislumbrar y comprender la conflictividad social» (González, 2018, p. 14).

Las capacidades desiguales de los territorios definen las posibilidades de desarrollo humano en la población, porque tienen que ver con el acceso a la educación, al empleo, a servicios de salud y comunicación. En el territorio mexicano podrían identificarse territorios ganadores y perdedores en función de la relación de cada una de las 32 entidades federativas con el sistema económico imperante. Quizá, más allá de las brechas regionales que caracterizan a México, es preciso mencionar que en el país viven 11 millonarios y más de la mitad de la población se encuentra en condiciones de pobreza extrema (Díaz, 2001, p. 17), caracterizada por carencias básicas, imposibilidad para incorporarse al sector formal de la economía, sin opciones educativas, aunado a estigmas de criminalización de clase y raza.

En este escenario de desigualdad, el Índice de Desarrollo Humano (IDH) 2016 (PNUD, 2016) identifica mejores condiciones de vida, empleo y capacidades productivas en entidades como Monterrey, Guadalajara y Ciudad de México. En otro extremo los más altos índices de analfabetismo, pobreza y desempleo, se localizan en entidades como Chiapas, Oaxaca y Guerrero, casualmente son territorios donde vive la mayor parte de la población indígena de México.

El tema de las brechas territoriales es una de las evidencias de la desigualdad, y por lo tanto, de violencia estructural, por ejemplo, en los territorios indígenas se ha vivido despojo de recursos naturales, desempleo y expulsión de la población a otras entidades, a la frontera norte e incluso a Estados Unidos y Canadá. En este sentido, el territorio es un escenario de las relaciones sociogeográficas entre lo local y lo global 
(Gledhill, 2016), y al mismo tiempo, es una unidad de análisis a partir de la cual podemos observar la pluralidad de "violencias» y explorar como se entrecruzan las dimensiones de violencia estructural y directa, para identificar el nivel de riesgo y criminogénesis (causas de los delitos) en los territorios.

En esta perspectiva del territorio, la violencia es localizada y tiene múltiples expresiones. El riesgo en los territorios comúnmente se mide en los actos delictivos; pero en este punto, es conveniente distinguir el delito y la violencia. El delito es un acto que trasgrede la ley y no en todos los casos es cometido con violencia, mientras la violencia no se limita al uso de la fuerza, sino a la posibilidad o amenaza de usarla (Fernandiz y Feixa, 2004). Por lo tanto, el uso de la violencia no es exclusivo de los actos delictivos, ni en todos los actos delictivos se emplea la violencia.

Con respecto a los actos delictivos, el reconocido criminólogo mexicano Sergio García Ramírez ${ }^{1}$, insiste en la gravedad de la relación entre delito y violencia, porque no sólo presenciamos el aumento de los actos delictivos, sino también el aumento de la intensidad de la violencia. La criminodinámica o forma en la que se comete el delito, indica que la intensidad de la violencia cada vez es mayor, así como los índices de delitos y las víctimas.

Quizá un hito en la historia de la violencia directa en México, fue el año 2006, cuando se declara la guerra contra el narcotráfico, en ese período los actos violentos asociados a estos grupos se caracterizaron por ser cada vez más sanguinarios y crueles, porque no bastó con quitarle la vida a las víctimas, sino que también los deshumanizaron, los despojaron de toda dignidad humana, Carlos Sandoval García expone en detalle este hecho:

Felipe Calderón (2006-2012) llega a la presidencia de México [...] emplea las fuerzas armadas (el ejército, la fuerza aérea y la marina) en la lucha contra el crimen organizado [...] La cifra oficial de personas desaparecidas durante el sexenio de Calderón fue de 24 091, de acuerdo con la Comisión Nacional de Derechos Humanos (CNDH) [...] lo cierto es que la incautación de sustancias ilícitas y la persecución de líderes de los carteles no son suficientes para provocar cambios en el comercio de sustancias ilícitas y en la violencia ejercida por el crimen organizado (Sandoval, 2015, pp. 41-42, 46).

Respecto a los altos niveles de violencia en México, John Gledhill sostiene que el aumento de violencia tiene que ver con el crecimiento de la economía de la droga, junto con una serie de actividades ilegales vinculadas a este mercado:

Los niveles de violencia aumentaron en la medida en que una serie de carteles rivales competían por el control de las rutas de trasbordo, las zonas de producción de marihuana y adormidera, y las instalaciones de procesado de cocaína y de fabricación de metanfetamina. Se escindieron cárteles más pequeños de las originarias organizaciones madre (Gledhill, 2016, p. 149).

Gledhill ha identificado que a partir de la lucha contra el narcotráfico $(2010,2016)$, en 2006, los gobiernos han usado el miedo para amenazar, persuadir y coaccionar a los ciudadanos, con el propósito de legitimar administraciones de gobierno, prometiendo seguridad, a pesar de que existan casos documentados del empleo de violencia política y alianzas entre actores políticos y crimen organizado para controlar ámbitos locales:

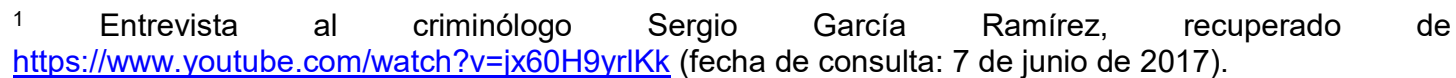


[...] combinando el apoyo material a las campañas electorales de los políticos con amenazas al electorado y actos esporádicos de violencia política contra determinados candidatos concretos, primero la Familia Michoacana y luego -de manera todavía más exhaustiva- los Caballeros Templarios llegan a adquirir el poder no sólo de determinar quién ganaba las elecciones locales, sino incluso qué candidatos se les permitía presentarse a ellas (Gledhill, 2016, p. 223).

Durante el período del Presidente Enrique Peña Nieto 2012-2018, el incremento en la tasa de prevalencia delictiva siguió y en algunas entidades alcanzó hasta un 50\% de 2012 a 2017, como en el Estado de México que en 2012 tenía una tasa total de prevalencia de 30920 y en 2017 llega a 47648, cifras de la Encuesta Nacional de Victimización y Percepción sobre la Seguridad Pública (ENVIPE, 2012, 2017). Las tasas más altas de prevalencia delictiva, cuyo aumento va del $58 \%$ al $21 \%$ en este periodo, se localizan en las siguientes entidades: Guerrero, Estado de México, Tabasco, Tlaxcala, Chiapas, Yucatán, Campeche, Baja California, Morelos, Aguascalientes, Colima y Jalisco.

Ante la delincuencia y la violencia, la población recurre a estrategias de disuasión del delito tales como: la compra de equipo, armamento e infraestructura militar; cámaras de seguridad y vigilancia, circuito cerrado de televisión (CCTV), además de los gastos más altos en seguridad privada. Estos consumos no están al alcance de toda la población (Valenzuela, 2016, pp. 30-35) dadas las condiciones de desigualdad del país.

El acceso a las tecnologías de vigilancia y seguridad y a equipo militar no son recursos exclusivos del estado, el crimen organizado también cuenta con la más alta tecnología y equipamiento, a un punto en que las fuerzas desiguales entre la seguridad pública y el crimen organizado, elevan la balanza hacia impunidad. La violencia inusitada e incontrolable del crimen organizado ha sido motivo para legalizar la nueva Ley de seguridad interior, que permite la militarización del país y el control del orden por vías represivas.

La imagen de la violencia y el crimen se ha vuelto cotidiana, normalizada por los medios de comunicación, debido a la cantidad de contenidos violentos y las formas en que se proyecta la intención de daño, furia y sometimiento del otro, de manera insensible; o bien, mostrando un tipo de violencia justiciera e inclusive heroica.

Los medios de comunicación han sido cómplices de la deshumanización, cuando contemplan y trasmiten actos de violencia y crimen sin siquiera intervenir. Con el uso de las nuevas tecnologías, los medios de comunicación tradicionales perdieron el control de la opinión pública, y se desató otro tipo de violencia, las imágenes de la violencia del crimen organizado y también violencia del estado.

Pareciera que las imágenes de la violencia son cada vez más atroces, como en el caso de los ajustes de cuentas que involucran a los cárteles de la droga, las fosas comunes, los desmembramientos que entran dentro de una larga lista de usos intencionales de la fuerza. Por otro lado, los mensajes de las narcomantas que circulan libremente en las redes sociales y youtube, se han tornado parte de un proceso comunicativo, de acuerdo con Gledhill:

En la guerra que libra el narcotráfico del siglo XXI, la violencia ha adquirido un carácter comunicativo: se utilizan cadáveres decapitados y desmembrados, junto con pancartas colgadas en los puentes, para enviar mensajes al enemigo y a la población en general (Gledhill, 2016, p. 221). 
Con la intensificación de la violencia, también ha habido una intensificación de las tecnologías de vigilancia y la violencia también ha tenido un amplio uso en los medios de comunicación para entretenimiento de las masas, condición que ha contribuido a su normalización.

Las tecnologías de vigilancia y comunicación no son exclusivas del Estado, también son empleadas por las organizaciones criminales para propagar el terror entre sus enemigos y también entre la población, como una muestra de su poder. Estos dispositivos proyectan imágenes y mensajes de terror, que provocan miedo y pánico social, emociones que a su vez son usadas por los partidos políticos y gobernantes para persuadir a los ciudadanos e imponer agendas políticas. Quizás sobra decir, que la difusión masiva de escenas sangrientas tiene libre acceso en México y alcanza miles de reproducciones en minutos.

\section{La violencia invisibilizada, normalizada y justificada}

La violencia cotidiana y la delincuencia han contribuido a la normalización de la violencia, al debilitamiento de los vínculos sociales; pero también provocan miedo y pánico social. En la dimensión de la violencia estructural hay sectores de la población que han sido señalados como doblemente vulnerables. Solo por su condición de raza o clase social ya heredan una condición de sometidos. En el caso de las mujeres, también se ha llegado a identificar una triple vulnerabilidad, en función de su clase, raza y género.

$Y$ es que en territorios donde hay delincuencia y pobreza predominan los delitos como secuestro, trata de personas y múltiples violaciones a los derechos humanos. En ocasiones, la característica de los delitos impide la denuncia. Los sectores más vulnerables siguen siendo los más pobres, como: los migrantes, los pueblos originarios, campesinos y población en condiciones de pobreza extrema (Gómez y Almanza, 2016, p. 150). Carlos Sandoval Gómez, menciona algunos ejemplos:

[...] las estadísticas oficiales de violaciones de derechos humanos están lejos de registrar la mayoría de los casos y la impunidad suele ser una tendencia recurrente. La desaparición de los 42 normalistas de Ayotzinapa rememora el asesinato de los 72 migrantes de San Fernando Tamaulipas y otros cientos o miles de homicidios ocurridos en México en los últimos casi 10 años (Sandoval, 2015, p. 48).

Si bien, la violencia estructural ha sido ignorada, normalizada e incluso justificada a través de la historia y la costumbre, también hay casos de violencia directa que sufren diversos sectores de la población, como pasa con los migrantes indocumentados, quizá sea de las menos evidentes debido a las escasas estadísticas y los números no llegan a reflejar la vulnerabilidad en los territorios de paso de los migrantes; no obstante, algunas etnografías han mostrado evidencias de como el crimen organizado se vale de la vulnerabilidad de sus víctimas, "...aprovechan la fragilidad jurídica y la exclusión cívica de los inmigrantes que no tienen documentos para poder someterlos a unas condiciones semejantes a la esclavitud» (Izcara y Andrade, 2016, p. 12).

Alrededor de la población migrante centroamericana indocumentada, se ha creado todo un mercado ilegal favorecido por la clandestinidad de los lugares de tránsito, la impunidad, la criminalización de la condición indocumentada del migrante, 
la incapacidad de las instituciones para reconocer a los migrantes como víctimas y su condición que ya es objeto de sospecha en algunos territorios de paso.

Entre la larga lista de abusos y violencia contra los migrantes indocumentados, las investigaciones exponen los siguientes: el pago por derecho de paso, palizas, mutilaciones, asesinatos, secuestro, prostitución, pornografía y trata de personas (Casillas, 2016). Los territorios huésped y los territorios de tránsito de migrantes son lugares de alto riesgo por la violencia y delincuencia que existe.

En el caso de población en condiciones de pobreza extrema, niños y jóvenes son vulnerables, víctimas y reclutados por el crimen organizado, narcotraficantes 0 redes de trata de personas, algunas transgresiones han sido difundidas por las redes sociales, a través de testimonios anónimos de las víctimas que logran escapar. En estas situaciones, puede verse la combinación de la dimensión estructural y directa de la violencia, debido a que los delitos contra los jóvenes son favorecidos por las condiciones de desigualdad y precariedad de los territorios.

La situación de los jóvenes en México no es nada sencilla, en los análisis de la OCDE, ya plantea que todos nacemos iguales, pero no todos nacemos con las mismas oportunidades, y es que de acuerdo con estimaciones del Education at a Glance de 2018, en 2017 sólo el $17 \%$ del grupo de edad entre 25 a 64 años, lograron estudiar la universidad, $13 \%$ de la población no tuvo acceso a la educación y el $17 \%$ sólo logro estudiar la primaria (OCDE, 2018, p. 54).

En los territorios de alto riesgo donde la población no tiene oportunidades de estudiar, trabajar, ni de acceso a la justicia, los pobres son criminalizados y en general se encuentran en riesgo de ser secuestrados y reclutados por organizaciones delictivas. De acuerdo con datos de la Secretaría de Gobernación, de 37435 desaparecidos, 6 de cada 10 son jóvenes (Martínez, 2018).

Martín Barbero considera que la criminalización de los jóvenes es parte de la justificación de la sociedad, para evadir la responsabilidad de otros grupos de edad y de las instituciones:

... la preocupación de la sociedad no es tanto por las transformaciones y trastornos que la juventud está viviendo, sino más bien por su participación como agente de la inseguridad que vivimos y por el cuestionamiento que explosivamente hace la juventud de las mentiras que esta sociedad se mete a sí misma para seguir creyendo en una normalidad social que el descontento político, la desmoralización y la agresividad expresiva de los jóvenes están desenmascarando (Barbero 1998, p. 23 citado en Reguillo, 2000, p. 46).

Alfonso Valenzuela (2016), expone los riesgos de violencia juvenil en entidades como Morelos y Diego Molina Rodríguez (2012), la influencia de la narcocultura en Sinaloa, ambos identifican la influencia de la violencia global y la falta de opciones para el futuro en el caso de los jóvenes herederos de la pobreza. Sobre la influencia de la narcocultura en los niños y adolescentes de Sinaloa, Diego Molina señala dos condiciones de riesgo que involucran a los adolescentes con la violencia: los narco juniors y los jóvenes sin oportunidad que son vulnerables a la captación del narco:

Los jóvenes no encuentran respuestas a sus inquietudes educativas, no consiguen empleos dignos y bien remunerados y ven que permanentemente la impunidad es un rasgo social que protege los comportamientos delictivos; hay una desmedida introducción de armas de fuego al territorio sinaloense y proliferan las tienditas para narcomenudeo (Molina, 2012, p. 154). 
En sus acercamientos a las culturas juveniles, Molina (2012) y Rossana Reguillo (2008) coinciden en que las expresiones de violencia juvenil son formas de manifestar el malestar contemporáneo ante la carencia o insuficiencia de lenguajes para expresarlo y ante la falta de oportunidades que existen en ciertos contextos. Rossana Reguillo considera que la juventud es un proceso clave para comprender los lenguajes de la violencia y en esta etapa los jóvenes están más vulnerables por: la precariedad estructural, la precariedad del yo, la ausencia o debilidad de políticas sociales que favorecen la exclusión y el quiebre o crisis de las instituciones (Reguillo, 2008, p. 139).

Reguillo (2008), Molina (2012), Saravi (2015) y Valenzuela (2016), apuntan a la desigualdad y la falta de oportunidades como las causas de los bajos niveles de acceso a la educación superior y al acceso al mercado laboral informal; condiciones, que han dejado poco margen al funcionamiento social de los jóvenes y de alguna manera los empujan a la migración, a ser captados por el crimen organizado, el narcotráfico, en un entramado complejo, sistémico y multidimensional de marginación, riesgo y vulnerabilidad (Reguillo, 2009, p. 41), se trata de juventudes fragmentadas, marcadas por la vulnerabilidad y la desventaja durante la transición a la adultez (Saravi, 2015, p. 14).

Aunado a la incertidumbre por el futuro y la violencia de los territorios, existe descontento, frustración y miedo por los riesgos ante la violencia y delincuencia. En la apreciación de John Gledhill, el miedo es una limitación para lograr el desarrollo humano de las poblaciones que viven en entornos violentos (Gledhill, 2016) y «la seguridad es un derecho fundamental» (García, 2017, p. 9); en consecuencia, la violencia local afecta el desarrollo pleno del potencial de todos los grupos de edad.

Sobre la violencia juvenil los jóvenes pueden ser víctimas y protagonistas; sin embargo, la violencia juvenil tiene múltiples ángulos: los delitos cuyas víctimas y victimarios son los jóvenes; la reproducción y normalización de la violencia en la escuela; la falta de sentido de pertenencia a la familia y a la comunidad (la erosión del «nosotros»), la creciente sensibilidad e incertidumbre y finalmente, el empleo de la violencia para sentirse capaces de protegerse.

Como vemos en este apartado, ante el tsunami de violencias nadie está a salvo, los feminicidios también son todo un tema y cada vez surgen nuevos actores y escenarios. Y los efectos de la violencia en los sistemas socioterritoriales van en dos direcciones opuestas: una es la destrucción de la cohesión social y debilidad de los vínculos en las comunidades locales, y en el otro extremo, surgen nuevas formas de cohesión ante la amenaza que representa la violencia y cada vez existen más grupos de civiles decididos a defender sus territorios, como en el caso de Cherán, un pueblo purépecha, en Michoacán, una de las entidades más violentas del país, se levantó en armas el 15 de abril de 2011 para luchar por su autogobierno y desde entonces ha disminuido la violencia.

Otros ejemplos de organización colectiva para hacer frente a la delincuencia y la inseguridad, son la creación de viviendas dentro de sistemas cerrados, como las privadas, los condominios y unidades habitacionales amuralladas, empleo de seguridad privada para controlar los accesos, uso de tecnologías de vigilancia y el pago a elementos de seguridad pública para cuidar barrios y colonias. 


\section{El miedo colectivo y sus usos políticos}

El interés en el estudio de las emociones, como categoría de análisis en las ciencias sociales, ha sido expuesto desde distintas disciplinas como la psicología, la antropología, la economía, la filosofía y la ciencia política. Descartes fue el primero en identificar las emociones (Elster, 2007, p. 168), a partir de la perspectiva primero de la elección racional y luego de la filosofía, John Elster explica que las emociones influyen en las acciones y elecciones de los individuos, porque no siempre tienen información completa y eligen en función de sus creencias (Elster, 2007).

Tanto desde la economía (Elster, 2007), como desde la psicología (Barrera, 2010), las emociones implican cambios fisiológicos, guías para la acción individual (impulsos) y colectiva, en valencias que fluctúan entre respuestas positivas y negativas. Elster ha asociado las elecciones con las emociones y la acción y reconoce que las emociones están influidas por la cultura.

Para la antropología, y en especial para la antropología política, las emociones sirven para explicar el simbolismo político y diversas formas de control tanto de sociedades "primitivas», como de modernos sistemas políticos (Cohen, 1979). A partir del interés de antropólogos políticos como Abner Cohen, Marc J, Swartz, Victor Turner y Arthur Tunden, surge toda una tendencia teórica sobre la relación del poder, el conflicto y los símbolos.

Parte del legado teórico de la Escuela de Manchester de la que viene Max Gluckman, Abner Cohen, Marc J, Swartz, Victor Turner, Arthur Tunden y también John Gledhill, existe dimensión política en todas relaciones no políticas, además de que lo político puede explicarse en su contexto sistémico para conocer el sentido de las acciones (Gledhill, 2000). Con estos planteamientos podemos ilustrar la dimensión política de la violencia estructural y el simbolismo político se vuelve relevante para comprender las emociones vinculadas a la hechicería, brujería, creencias animistas y en el caso de que nos ocupa, las emociones relacionadas con la violencia y la delincuencia.

Más tarde, otro antropólogo político Marc Abélès analiza dimensiones simbólicas de poder en la vida cotidiana que llega a relacionar con la macroestructura política a través del análisis de las ceremonias políticas y los ritos políticos (Gledhill, 2000) y estudia e interpreta los mensajes de la elite política y las emociones que provocan los actores políticos, a través, del manejo del simbolismo político como fuerza legitimadora ante los ciudadanos.

La violencia y las creencias sobre la violencia provocan una serie de emociones que oscilan entre el miedo, pánico social y miedo colectivo, que los actores políticos han utilizado para generar empatía, recuperar la credibilidad perdida de los electores y ciudadanos, mediante medidas encaminadas a terminar con la violencia y la delincuencia; no obstante, el miedo también es una idea política, en cuanto ha sido empleado como un dispositivo de control y disciplinamiento, para mantener cierto orden, como describe Fabián González Luna:

El miedo representa un factor primordial de control social y de legitimización de las formas de poder establecido, que además coadyuvan al fortalecimiento de políticas de intervención militar y policial que son recursos materiales e ideológicos que imponen y garantizan el orden social... Existe una morfología del miedo en la ciudad, es decir hay zonas, lugares específicos que en la representación social se elaboran como "espacios de miedo" (González, 2018, p. 198). 
Ya en otros lugares y momentos se han realizado análisis sobre el uso del miedo como un dispositivo de control y poder en los territorios donde hay altos niveles de inseguridad, donde "...el miedo se vive como una realidad cotidiana en cada uno de los espacios de reproducción social y se representa como una ausencia de seguridad en cada instancia de una vida vivida como una experiencia angustiosa» (Useche, 2008, p.1).

Una perspectiva de la psicología, define al miedo como reacción física:

El miedo [...] se activa mediante un estímulo amenazante produce una hormona llamada vasopresina, la cual desencadena, además del miedo, también ansiedad, y dispone a la persona para la lucha, la huida y la evasión del dolor, y todas las funciones de conservación del individuo y de la especie (Barrera, 2010, p. 6).

Para Juan Antonio Barrera Méndez, el miedo es una emoción primaria que tiene funciones biológicas y adaptativas, sirve para alertarnos del riesgo real o supuesto, presente o futuro y se manifiesta tanto en animales como en el ser humano. El pánico es una forma extrema de miedo, ante la intensificación de peligro, con frecuencia es colectivo y contagioso y el miedo colectivo tiene que ver con el miedo compartido por parte de un grupo o una sociedad (Barrera, 2010, p. 8).

Entonces podemos decir que el miedo es una emoción producida por la conciencia de riesgo o las creencias que desencadenan emociones, algunos ejemplos los tenemos en la cultura y en la ficción que llegan a provocar perturbaciones emocionales (Elster, 2007, p. 165).

El pánico es una expresión del miedo ante una amenaza de riesgo y plantea que «en realidad las personas responden de manera emocional a las circunstancias que se encuentran en su entorno, especialmente si está involucrado el poderoso sentimiento del miedo...» (Valenzuela, 2016, p. 63).

El miedo y la esperanza son emociones sostenidas en la creencia de posibilidades «estas emociones son generadas por la idea de cosas buenas o malas que pueden o no ocurrir en el futuro» (Elster, 2007, p. 169), mientras la desilusión «es la emoción que se produce cuando un suceso positivo esperado no se materializa» (Elster, 2007, p. 169).

De esta manera, el miedo, el pánico y el miedo colectivo se refieren a distintas intensidades de temor y unidades de análisis (individual, grupal y colectivo) y sirven de guía para la acción en las relaciones sociales, de tal manera, que el estudio de las emociones suele utilizarse en las mediciones de desempeño económico y la felicidad.

Como ya hemos propuesto, el miedo también fluctúa entre valores positivos y negativos, de acuerdo con los planteamientos de los autores mencionados, el miedo positivo puede ser un mecanismo adaptativo, pero el miedo negativo, puede limitar el pleno desarrollo del potencial humano, como lo explica Gledhill a partir de su referencia al concepto de seguridad humana propuesto por el PNUD, y señala lo siguiente:

Al vincular los temas de violencia y conflicto a la privación producida por la pobreza, el paradigma de la seguridad humana propone un enfoque holístico de la búsqueda de soluciones, argumentando que las personas sólo pueden realizar su potencial como seres humanos si se las libera tanto del temor como de la necesidad. No es posible resolver los problemas de seguridad personal dándole a una persona un puesto de trabajo si esa persona va a morir prematuramente por desnutrición o de una enfermedad que no puede curarse por falta de hospitales, o si es probable que esa 
persona sea asesinada en su camino del trabajo a casa por criminales, por paramilitares o por un miembro de la policía local o del ejército (Gledhill, 2016, p. 23).

En esta reflexión de Gledhill ilustra una clara relación entre la dimensión estructural y directa de la violencia, y en esta línea argumentativa, el autor plantea la constante violación al derecho de seguridad humana en grandes sectores de la humanidad. Y el temor o miedo, como unidad de análisis, también puede servir para explicar las diferencias con respecto al desarrollo humano, en términos del PNUD.

Los especialistas en el estudio de la violencia hallan que en territorios con altos niveles de riesgo, también hay niveles proporcionales de miedo colectivo y pánico social, Ferrandiz y Feixa (2004), González (2018), Molina (2012), Recansens (20052006), Reguillo (2000, 2003 y 2008) y Valenzuela (2016), en estos territorios, los jóvenes sólo tienen dos opciones el uso de armas o aislarse.

El miedo induce a huir o a pelear (Elster, 2007) y quizá esta sea una alternativa para explicar la reproducción y normalización de la violencia en territorios de alto riesgo, porque las distintas manifestaciones de violencia inducen a la gente hacia el individualismo, aislamiento, migración, anomia social e incluso al suicidio o al uso de la violencia como recurso de defensa.

En la perspectiva de algunos especialistas, las personas que sienten miedo pueden ser fácilmente influidas a seguir las reglas de las autoridades locales (Barrera, 2010), o en este caso a aceptar las disposiciones de los gobernantes, sin cuestionar, como en situaciones de terrorismo, delincuencia, crisis política y económica. En territorios con altos niveles de violencia, los ciudadanos viven en un estrés permanentemente porque tienen conciencia de que pueden ser víctimas potenciales de algún delito hasta en sus propios hogares. Uno de los trabajos académicos que analiza esta relación, es el de Alfonso Valenzuela, quien explica el miedo como un dispositivo de control político:

[...] el miedo ha adquirido una dimensión política fundamental en las últimas décadas, especialmente a partir de la guerra contra el narcotráfico. En última instancia, el miedo se ha convertido en una herramienta para imponer una agenda económica ortodoxa a una sociedad paralizada por la violencia y que, no obstante, da aún muestras de solidaridad, resiliencia e indignación ante las injusticias y las violencias del Estado (Valenzuela, 2016, p. 21).

El miedo como sentimiento de vulnerabilidad colectiva ante la violencia y la delincuencia, ha sido manejado hábilmente por los gobiernos y durante los procesos electorales, para legitimar campañas, candidatos y partidos políticos y para imponer nuevas agendas políticas como la militarización del país, como ha pasado con la nueva Ley de Seguridad Interior ${ }^{2}$, vigente a partir del 21 de diciembre de 2017, que habilita la intervención de las fuerzas armadas para controlar o reducir las amenazas en el las entidades, municipios, zonas o áreas geográficas del país, a partir de la defensa, seguridad y protección de la población.

Podría ser ilustrativo mencionar que el uso de la violencia del estado ha tenido que ver con la deslegitimación de los gobiernos mexicanos y la sospecha de fraude electoral, como en las elecciones de 2006. Haciendo un poco más de historia, en los procesos electorales federales posrevolucionarios y hasta las elecciones del 1 de julio de 2012, ha habido incidencias, quejas documentadas con respecto a la transparencia

2 Cámara de Diputados del H. Congreso de la Unión, Ley de Seguridad Interior: http://www.diputados.gob.mx/LeyesBiblio/pdf/LSInt 211217.pdf 
del proceso electoral, altos niveles de abstencionismo y coerción, así como acontecimientos que ponían en tela de juicio la legitimidad de los gobiernos.

Lo más común ha sido que en los procesos electorales los candidatos utilicen las emociones buscando la empatía de los electores, dice John Gledhill, como una "cultura esotérica" de liderazgo político, que impacta creando una seudorealidad, a modo de estrategia para movilizar a los electores y maximizar votos (Gledhill, 2000, p. 24); mientras, en el siguiente peldaño, entre los gobernantes, ha predominado el lema de "mano dura", como amenaza del uso de la violencia del estado contra los infractores o detractores de los gobiernos.

En la apreciación de Gledhill $(2010,2016)$, los esfuerzos de los actores políticos son intentos sofisticados y neoliberales de recuperar la credibilidad, combinando la ayuda con la violencia represiva. Con esta tendencia, se han intensificado los programas de transferencia condicionada al tiempo que las estadísticas de desaparición forzada aumentan, así como la incidencia delictiva, la represión policial y la segurización con apariencia de pacificación.

Marc Abélès, también reconoce como los actores políticos se valen de múltiples medios para enviar mensajes a los ciudadanos y expone los ritos políticos, a través de los cuales, los gobernantes reafirman pacíficamente su autoridad. En México esos mensajes que envían los gobernantes han sido más que evidentes en los altos gastos en publicidad. Entre los ritos políticos más comunes está la entrega de apoyos asistenciales a población vulnerable en ceremonias públicas y transmisiones en distintos medios publicitarios. Agregaremos la apropiación de símbolos populares y culturales para uso político, que ya menciona Gledhill, como la apropiación de la imagen del célebre revolucionario Emiliano Zapata:

[...] para comprender el poder emotivo de los rituales políticos, donde las multitudes son arrastradas por los símbolos implicados mientras se muestran totalmente cínicas respecto al papel de las figuras públicas civiles, o militares que ofician la ceremonia. El poder emotivo de la figura de Emiliano Zapata para los mexicanos de clase baja radica en la autenticidad de su «representación» del pueblo. Como líder popular traicionado y asesinado por la elite política de la sociedad posrevolucionaria, Zapata no es simplemente alguien que no se «vendió» al pueblo, sino que representa su traición colectiva (Powell 1996, 52-53, citado en Gledhill, 2010, p. 227).

Los gobiernos usurpadores del papel de revolucionarios, por un lado, explotan las emociones que despiertan figuras como la de Emiliano Zapata, mientras en sus acciones protegen el despojo a los campesinos y pueblos originarios para favorecer a las empresas privadas, como en el caso del monopolio del estado en la industria energética durante la administración presidencial de Enrique Peña Nieto y que ilustra con detalle Gledhill (Gledhill, 2016, p. 256).

El manejo de las emociones ha sido fuente de poder de las elites políticas y los gobiernos del «partido oficial» han sostenido sus estructuras políticas en una maquinaria de opresión, que no sólo ha servido para asegurar la violencia estructural, a través de políticas asistenciales, también han usado la violencia del estado para pacificar a los sectores de la población que representan riesgo para los intereses neoliberales, promoviendo el miedo para imponer líderes y autoridades.

Los gobernantes no sólo se han caracterizado por el combate contra los actores de la violencia, también han fabricado algunos de estos actores y han sido actores de la violencia, para asegurar el control de los territorios. La segurización, ha consistido en la criminalización de movimientos sociales, ecologistas, periodistas u 
oposición, que ha desplegado una especie de terrorismo de estado, como en el caso del Ejército Zapatista de Liberación Nacional, Chiapas, 1994.

Respecto a las propuestas relativas al endurecimiento de las penas, quizá también se ha dejado un poco ambiguo el tema de la prevención del delito, olvidando aquel viejo lema de los penitenciaristas de «más vale prevenir que readaptar», y no sólo es relevante por los altos costos económicos, sociales y humanos que implican las violencias en los territorios; sino, porque la prevención es el puente entre la violencia directa y la violencia estructural.

El endurecimiento de las penas solo representa el camino a un callejón sin salida, sobre todo si consideramos que el miedo paraliza a las víctimas, el estado esta deslegitimado, y las victimas no son reconocidas como causa del delito, sino como consecuencia. Asimismo, la corrupción y la impunidad han mermado las capacidades del sistema de seguridad y de justicia y la sobrepoblación en las instituciones penitenciarias, abre la posibilidad de prelibertades cuando los internos aún no están preparados para reintegrarse funcionalmente en la sociedad. Aunado a lo expuesto, la posición marginal de los preliberados, por su condición de exinternos, llega a ser con frecuencia un factor motivacional de reincidencia delictiva.

En cuanto a la violencia expuesta en los medios de comunicación, es claro que existe una doble hermenéutica, al magnificar lo que se considera una amenaza o riesgo en los territorios (que a menudo tiene que ver con intereses económicos y políticos), esta posibilidad se enuncia en dos proverbios «el miedo es a menudo más grande que el peligro» y "cuanto más miedo, más peligro» (Elster, 2007, p. 58). Elster, atendiendo a los efectos de la comunicación, Ilama la atención a que las emociones nos pueden conducir a creencias sesgadas, porque impiden recoger información suficiente; quizá habría que agregar que esta "inocente" doble hermenéutica no sólo fomenta el miedo, sino que contribuye a criminalizar a ciertos sectores y a legitimar las acciones de segurización o "pacificación" del estado.

\section{La panacea de la violencia de estado}

Hemos planteado como las violencias han sido un instrumento de poder y de control por parte del crimen organizado, el narcotráfico y del estado. Mientras el uso de la violencia del estado se ha justificado para poner fin a amenazas como la delincuencia, también alcanza a sectores de la población que representan un riesgo a los intereses del estado o del mercado. En el caso del crimen organizado y el narcotráfico que caracterizan ciertos territorios, cada vez representan un conflicto mayor que implica una peligrosa combinación entre falta de oportunidades y explotación, reclutamiento y una multiplicidad de delitos perpetrados contra los más vulnerables. Además, de la inseguridad que representan los delincuentes de cuello blanco. Estos diversos actores de la violencia, han contribuido a la cotidianeidad de la violencia y a su normalización; y mantienen el miedo colectivo.

La violencia de estado no tiene una fecha de nacimiento, porque en términos de los especialistas en el surgimiento del estado, es inherente a la formación de este orden y al mantenimiento de una jerarquía de poder. A pesar de que la violencia de estado no es nueva, en México suele vincularse a la represión de movimientos sociales, a partir de 1970 en Guerrero, 1994 en Chiapas y Michoacán en 2006 (Gledhill, 2016). 
Los hechos violentos en los que participaron las fuerzas armadas del estado en Guerrero y Chiapas llegaron a identificarse como crímenes contra la humanidad, genocidios y exterminios que han provocado despojos, desapariciones masivas, expulsiones, pánico social y al mismo tiempo han reproducido formas de violencia y vulnerabilidad de una parte de la población, principalmente de los campesinos, los pueblos originarios y los sectores más empobrecidos.

La violencia ejercida por el estado ha generado desplazamientos de la población tras la amenaza de las fuerzas del estado, desaparición forzada y de alianzas entre las instituciones de seguridad y organizaciones criminales, como describe John Gledhill: «Los militares y la policía no son, sin embargo, los únicos actores en una violencia que tiene un carácter político, y hay quejas cada vez más frecuentes de que el crimen organizado actúa en connivencia con los intereses políticos que dominan el estado» (Gledhill, 2016, p. 168).

El estado vive una crisis de credibilidad relacionada no sólo con la corrupción, la alianza con el capital y con el crimen organizado, sino también con la desaparición forzada y su incapacidad para proteger a los ciudadanos (Gledhill, 2016; Valenzuela, 2016). En este contexto, John Ghedhill rechaza la idea de que el carácter represor del estado tenga el propósito de "restaurar el imperio de la ley» porque este imperio no ha existido nunca y realiza la siguiente consideración:

Las élites mexicanas pretenden volver a imponer la autoridad estatal incorporando en las nuevas estructuras de gobernanza a algunos actores armados que tienen su origen en el mundo del crimen, tratando de asimilar a otros que también pueden hacer algo para reforzar el imperio de la ley a más largo plazo, y criminalizando aquellos movimientos sociales que constituyen potenciales impedimentos al avance inexorable de la acumulación de capital en las zonas rurales de México (Gledhill, 2016, p. 151).

A pesar del infructuoso despliegue de violencia, luchas y graves pérdidas, la respuesta del estado continúa siendo un panóptico, a través de tecnologías de seguridad y vigilancia, inversión en equipo militar; acciones que no han provocado cambios en la tendencia de la violencia, la delincuencia y la presencia de organizaciones criminales.

El caos provocado por la violencia ha abierto la caja de pandora, en términos de Alfonso Valenzuela (2016), el estado no logra controlar al crimen organizado porque además de tecnología y armamento cuenta la complicidad de políticos y cuerpos policiacos de distintos niveles de gobierno.

...el Estado se vuelve cada vez más represor (disciplinar) y controlador (la gente está dispuesta a renunciar a sus derechos fundamentales con tal de ver controlada la violencia) y, sin embargo, la paradoja radica en el hecho de que existen otros agentes con poderes análogos como grupos paramilitares y/o las organizaciones criminales, que también reprimen (a periodistas, políticos, policías o civiles), o bien controlan (territorios, economías locales, gobiernos estatales y municipales) ${ }^{3}$ (Valenzuela, 2016, p. 41) .

El empleo de la violencia legal contra los actos de violencia ilegal, no ha bastado para detener el crimen; no obstante, el uso de la violencia se legitima en el riesgo que representa el transgresor. Los panópticos, las tecnologías de seguridad y vigilancia para combatir la delincuencia, sólo han generado más costos económicos

\footnotetext{
${ }^{3}$ Las cursivas son del texto original.
} 
y sociales que han contribuido a profundizar la crisis de legitimidad del estado, en palabras de Gledhill:

México se ha convertido en un país en el que se criminaliza de manera rutinaria a los movimientos sociales genuinamente populares, al tiempo que se encarcela a sus líderes, mientras que aquellos que se dedican a actividades ilegales siguen prosperando bajo la protección de un estado que produce inseguridad en lugar de aliviarla (Gledhill, 2016, p. 197).

El despliegue de violencia del estado no ha disminuido la tendencia del aumento de la violencia y la delincuencia, como muestran las siguientes cifras:

En el nivel nacional en $33.9 \%$ de los hogares al menos una persona sufrió un tipo de delito, en el Estado de México y en el Distrito Federal el índice alcanzó $57.2 \%$ y 40.9 $\%$ de los hogares, respectivamente. La tasa de incidencia delictiva por cada cien mil habitantes es una de las mediciones estandarizadas en el nivel internacional, y mientras que el promedio nacional es del orden de 35139 delitos, en el Distrito Federal se dispara a 49198 hechos delictivos (Valenzuela, 2016, p. 139).

Las posturas ante la violencia y la delincuencia se encuentran divididas, mientras las clases alta y media claman por mayor castigo para los delincuentes, la población en condiciones de pobreza es criminalizada y el delito perpetrado contra estos no es perseguido. De tal manera, que en los territorios de alto riesgo se vive una especie de anomia y ruptura del tejido social, en estas sociedades cualquier extraño despierta sospechas y desconfianza, acentuando la discriminación y el racismo y xenofobia, como si los pobres fueran los culpables del deterioro social y de la erosión de las instituciones.

Estas posiciones y capacidades de las diferentes clases sociales han contribuido a que México la prevención del delito sea «precaución» y se vuelva una cuestión de clases sociales; la clase alta y media tienen posibilidades para invertir en alarmas, cámaras de video vigilancia y agencias de seguridad privada, la clase baja queda prácticamente desprotegida, sin la protección de la seguridad pública y sin acceso a la justicia.

De acuerdo con información que presenta Alfonso Valenzuela, en la última década, las familias mexicanas incrementaron su gasto en seguridad y vigilancia en $40 \%$ y México ocupa el tercer lugar en el mundo en la compra de equipo de seguridad:

En lo colectivo, ante la incapacidad de la seguridad pública por asegurar el orden, las respuestas se han concentrado en la fortificación de los vecindarios, en el cierre de las calles y en la contratación de agencias de seguridad privada ... la seguridad privada se ha erigido como un modelo alterno a las fuerzas del orden oficiales, como se evidencia en el estudio de la Asamblea Legislativa del Distrito Federal, el cual estimaba en 150 mil guardias de seguridad privados contra cien mil elementos de seguridad pública para dicha demarcación (La Jornada, 1998, citado en Valenzuela, 2016, p. 150).

Esta diferencia de acceso en sociedades profundamente desiguales es solo una distinción social más de clase y tiene que ver con esa dimensión estructural de la violencia. Tal parece que los más pobres son los más expuestos, criminalizados, objeto de segurización y sin acceso a la justicia. No obstante, estas diferencias no solo se ven entre clases sociales, sino también entre territorios.

En este orden de ideas, la antropóloga Elena Azaola, explica que la destrucción del tejido social ha facilitado la apropiación del espacio al crimen organizado y los territorios se van transformando en tierra de nadie, territorios sin ley 
o bajo la ley del más fuerte: «No hay trasgresión donde las normas no han sido apropiadas y dónde la sanción es débil. Se penetra así a un mundo donde todo es posible...» (Azaola, 2008, p. 263). En esta línea, Azaola no solo hace referencia a la delincuencia, sino también a la impunidad.

Un ejemplo de estas alianzas es el Estado de Coahuila, donde se han presentado graves acusaciones de crímenes contra la humanidad, ante la Corte Penal Internacional (Díaz, 2017), porque se han hallado lazos de asociación delictuosa entre organizaciones policiacas y cárteles de la droga. Se trata de poderes intermedios que el mismo estado creo para mantener la paz y el imperio de la ley, pero los poderes intermedios referidos rebasaron el poder de sus jefes y la pregunta qué habría que hacer ahora es ¿Quién sirve a quién?

El agravamiento de las penas se ha planteado reiteradamente como una solución al problema de la violencia y delincuencia desde escenarios políticos; no obstante, el sistema penitenciario en México ya enfrenta graves retos ante el crecimiento de la delincuencia y la sobrepoblación de las instituciones de readaptación. La tasa de encarcelamiento en México es de 196 por 100.000, más alta que la de Brasil (Gledhill, 2016, p. 40).

El problema común que ya presentan las instituciones penitenciarias ante la sobrepoblación y hacinamiento es que cuando los espacios se vuelven insuficientes, trasladan a los internos, y crean programas de "despresurización», a través de los cuales, otorgan beneficios de prelibertad (pueden compurgar una parte de su sentencia extramuros) masivos a «internos de bajo riesgo», cuyos delitos fueron tipificados como no graves. No obstante, en 2017 el sistema penitenciario en México ha mostrado una serie de problemáticas, entre las más fuertes destacan casos de motines en Tamaulipas y Veracruz.

El 7 de junio de 2017 murieron 7 personas y 29 internos se fugaron en posesión de armas de fuego para uso exclusivo del Ejército del Centro de Ejecución de Sanciones de Victoria (González, 2017); el 20 de junio de 2017 la policía federal trasladó 38 internos de alto riesgo del penal de Topo Chico en Veracruz, hacia penales de Guanajuato, Durango, Veracruz, Oaxaca y Michoacán “...con el fin de evitar nuevos incidentes violentos como la masacre registrada el 11 de febrero de 2016, la cual dejó 49 muertos y 34 heridos" (Carrizales, 2017). En el Centro de Readaptación Social de Acapulco, una riña dejó un saldo de 34 muertos y 32 heridos (Flores, 2017) "prisión tiene sobrepoblación de 27 \%: hay 2 mil 101, cuenta con lugar para mil 624" (De Dios, 2017).

De escenarios como estos podríamos hacer un largo inventario, contando solo las instituciones penitenciarias en lo que va del año. El externamiento masivo es un tema de alerta porque preliberan a internos para liberar espacio, el 7 de julio de 2017, Miguel Ángel Mancera Espinosa, Jefe de gobierno de la Ciudad de México, informó la posible liberación de 4000 internos de las instituciones penitenciarias de la capital de país (Redacción Proceso, 2017). Cada vez son más las preguntas que las respuestas, y al respecto tendríamos que plantearnos ¿qué nuevos riesgos suponen las liberaciones masivas en territorios caracterizados por la violencia y delincuencia?

La violencia y la delincuencia tienen características particulares en cada territorio, por eso el territorio es fundamental para pensar o repensar el tema de la prevención del delito, el cual constituye el vínculo que conecta las condiciones estructurales y con la violencia directa y la delincuencia. 


\section{7. ¿Prevención o precaución del delito?}

Como ya vimos, las emociones y la violencia pueden tomar valores positivos y negativos, como la violencia estructural «aceptada», justificada e institucionalizada (invisibilizada, dirigida a «educar» y «corregir») como pasa con la violencia intrafamiliar, aunque a veces llega a ser brutal y sádica.

La distancia entre la violencia «justificada» e «injustificada», supone la existencia de múltiples niveles intermedios de violencia, que implican distintas direcciones y cruces entre la dimensión estructural y directa, en la familia y otros espacios colectivos como la escuela, la calle, el barrio. Estos niveles intermedios de violencia implican distintas dosis de brutalidad. Esto significa que la violencia se mantiene y reproduce, a través de conductas colectivas en la familia, tradiciones culturales, y en los sistemas económicos y políticos.

Además del aumento progresivo de la delincuencia, hay un aumento en la intensidad de la violencia y nuevas formas de trasgresión, como el robo de información, las extorsiones, los asaltos a domicilio, el crecimiento de la delincuencia organizada alrededor de grupos vulnerables, secuestro y trata de personas, homicidio, robo de órganos, masacres, fosas comunes, entre otros. En esta carrera criminal las estrategias de control y prevención del delito no logran avanzar al mismo ritmo que la violencia y la delincuencia.

El estado no ha logrado diseñar políticas de prevención del delito capaces de combatir el origen la violencia y la delincuencia in situ, ni siquiera que consigan comprender la pluralidad de las violencias que afectan a los sistemas locales. Las medidas más comunes podrían clasificarse como precaución del delito, porque no atienden el origen la génesis o criminogénesis.

La incapacidad del estado para prevenir el delito, incrementa la posibilidad de que cualquiera pueda ser víctima, en este escenario los ciudadanos responden con acciones de precaución, defensa e incluso castigo. La precaución fomenta la individualización, el aislamiento, la desconfianza, tiene que ver con tomar medidas de seguridad individual, evitar lugares y horarios de riesgo. La defensa tiene que ver con el conjunto de acciones para protección individual o grupal, como portación de armas, uso de tecnologías y seguridad privada para salvaguardarse. $Y$ el castigo, ha sido una medida colectiva que surge de grupos que han decidido recuperar sus territorios y proteger a sus familias y comunidades.

Los programas y acciones calificadas como preventivas desde el gobierno, se refieren comúnmente a la reestructuración de los sistemas policiales y de justicia penal, sin que hasta ahora exista evidencia empírica de la disminución de la violencia y la delincuencia. Quizá, uno de los avances más importantes en este ámbito ha sido la creación de la Ley General para la Prevención Social de la Violencia y la Delincuencia ${ }^{4}$ en 2011 (LGPSVD), a partir de la cual se crea una subsecretaría y un Programa Nacional para la Prevención Social de la Violencia y la Delincuencia.

La LGPSVD establece en su artículo $2^{\circ}$ que «la prevención social de la violencia y la delincuencia es el conjunto de políticas públicas, programas y acciones orientadas a reducir los factores de riesgo que favorezcan la generación de la violencia y delincuencia, así como combatir las distintas causas y factores que la generan (LGPSVD, 2012)», el problema es que las instituciones y los diferentes

\footnotetext{
${ }^{4}$ Puede consultarte en la siguiente dirección:

http://www.shcp.gob.mx/LASHCP/MarcoJuridico/MarcoJuridicoGlobal/Leyes/370 lgpsvd.pdf
} 
niveles de gobierno no han logrado identificar las causas del delito, además colocan a la violencia y la delincuencia en el mismo paquete y cada organización estatal y municipal, sigue entendiendo lo que puede y lo que quiere. Para conectar las causas del delito y combatirlas habría que pensar en políticas diferenciadas, dada la particularidad del fenómeno (amalgama de las violencias) en cada territorio.

Ya el termino prevención es polisémico, debido a que se utiliza en diversos ámbitos y con variados fines, por ejemplo en lo que respecta a prevención social, prevención comunitaria, prevención del delito (Martínez y Aguilar, 2017, p. 197). A pesar de esta ambigüedad, con base en la ley referida, la prevención no sólo tiene que ver mecanismos para disuadir el delito antes de que suceda sino con combatir las causas, que como hemos planteado involucran a la dimensión de la violencia estructural, presente en la violencia cotidiana.

Existen otras nociones que contribuyen a fundamentar y clarificar esta perspectiva, como la de prevención pre-delictiva recuperada de Irvin Waller «a través de intervenciones que apuntan a la transformación de actitudes, estilos, entornos y patrones de vida individuales y comunitarios, además de la operación y las respuestas institucionales» (Martínez y Aguilar, 2017, p. 197). La prevención del delito tiene que ver con reforzar las anclas sociales de los niños y jóvenes. Ciertos especialistas en el tema se refieren a la prevención temprana de la delincuencia para hacer referencia a que no sólo se trata de disuadir, sino de que el niño construya lazos fuertes con su sociedad, a partir de la familia y el grupo social, «lugares» donde se forma a los ciudadanos.

De acuerdo con David P. Farrington (1999), debemos volver la vista hacia los niños y jóvenes, para arraigarlos y fortalecer el sentido de pertenencia a la sociedad, la cultura y el territorio. Significa, que se sientan identificados con sus grupos sociales desde la primera infancia para que tengan una integración social funcional, de esta forma las personas no tendrán incentivos para transgredir las reglas y podrán contribuir al bien común. Se trata de reconstruir la noción del «nosotros» que se erosionó con las violencias.

La prevención temprana tiene que ver con evitar que los niños sean víctimas y/o infractores, como en las famosas cadenas de violencia, donde la violencia se canaliza hacia el más débil. En esta línea argumentativa, la solución no está en el poder coercitivo del estado, en los sistemas penales de alta seguridad, ni en los mecanismos inhibidores o disuasivos de seguridad pública; la clave es visibilizar el hibridaje entre violencia estructural y la violencia directa en los territorios, a partir de espacios estratégicos, como la familia, la escuela y el grupo social.

Las confusión entre prevención del delito y precaución del delito, no es inofensiva, tiene un gran impacto en las instituciones encargadas de la prevención del delito, porque se mantiene el miedo colectivo, pánico social, aislamiento, desconfianza e inseguridad, y al mismo tiempo, se proporciona la justificación perfecta para la intervención represiva del estado, la preservación de élites políticas y la eliminación de amenazas a los intereses del estado. La confusión de términos justifica la falta de capacidades y evade la falla de nuestros gobiernos para combatir la criminogénesis y sobre todo, se culpa a los ciudadanos de sus desventajas heredadas y se legitima la meritocracia.

La inversión del estado en cuerpos de seguridad, armas y tecnología militar, no representa una ventaja cuando se utiliza en contra del pueblo y no se ataca el origen del problema, sino se utiliza para controlar el crimen organizado a favor de las élites políticas. Por lo tanto, la solución no es matar a todos, ni tampoco encerrar a 
todos, sino diseñar programas de prevención eficaces que identifiquen la criminogénesis de los territorios, como punto de partida.

La precaución del delito es sólo un privilegio de las clases sociales media y alta, que pueden invertir en seguridad privada y tecnologías de seguridad; mientras los más pobres no sólo son criminalizados, también los más vulnerables a ciertos delitos como: robo de infantes, robo con violencia, violaciones, secuestro, trata de personas, robo de órganos.

La segregación en los territorios de alto riesgo, contribuye a la destrucción de la cohesión y el sentido comunitario. Entre los especialistas en violencia, Valenzuela (2016) propone la reapropiación del territorio y la participación colectiva en la recuperación de espacios comunes, esto lleva a identificar capacidades colectivas que contribuyan a la seguridad de sistemas locales, mediante el control social del espacio.

Para Valenzuela (2016), el papel de la escuela y la cohesión social, se vuelven fundamentales en la prevención del delito y la recuperación del territorio. Un joven protegido, escuchado, que disponga de espacios para ser, hacer, estar, decir, sentir, y canalice su energía en el deporte, desarrolle de talentos artísticos y creativos y se nutra del valor de las ideas e intervenciones pedagógicas, tenderá a desarrollar plenamente su potencialidad y competencias para el futuro.

A partir de estas aproximaciones podemos ver al territorio como un elemento integrador e identitario, y su reapropiación como una estrategia para el combate colectivo de actividades ilícitas y delictivas (Valenzuela, 2016). Y a la prevención (de la violencia y la delincuencia) como el prisma que identifica la pluralidad de las violencias, a partir de la lectura del territorio, dada la diversidad de expresiones de las violencias y las desigualdades que caracterizan a México.

\section{Conclusiones}

A manera de conclusión, reiteramos que la violencia es una construcción social porque las sociedades van enseñándola, reproduciéndola o permitiéndola, a través de los sistemas económicos, políticos y culturales, como en el caso de la violencia intrafamiliar, los patrones se repiten en los hijos como golpeadores y las hijas golpeadas. Y en el caso de las famosas cadenas de violencia, donde la violencia se dirige al más débil.

La violencia es un indicador de la crisis social y moral en el territorio, pero también es producto de la violencia estructural, invisibilizada e institucionalizada. La dificultad para reconocer esta dimensión de la violencia ha contribuido a su reproducción, preservación e intensificación. Y los riesgos de ver la dimensión directa y estructural de forma aislada, implican el diseño de políticas de prevención y control fragmentadas, más parecidas a la precaución del delito y no logran atender la criminogénesis, ni disminuir los niveles de riesgo en los territorios, como ha ocurrido hasta hoy en México.

El incremento de los actos delictivos y la institucionalización de la violencia han contribuido a intensificar la violencia estructural y la violencia directa. Como resultado de las condiciones de violencia y delincuencia, el miedo colectivo y el pánico social han sido dispositivos de control y poder de las élites políticas. El empleo de la violencia de estado ha ocasionado la devastación de territorios y el exterminio de 
poblaciones completas, considerando, que las fuerzas militares han sido asociadas a la desaparición forzada, al despojo y represión de la población en lo que va del siglo XX y XXI.

En los territorios de alto riesgo existe una creciente desconfianza hacia el estado y los niveles de violencia y delincuencia fracturan y destruyen la cohesión social. Los delincuentes de cuello blanco, el crimen organizado y el narcotráfico están tomando el control del espacio público y lo están haciendo privado, como un área de la que se posesionan. Así, la gente empieza a perder los espacios públicos por miedo.

La espacialización de la violencia y la delincuencia, solo degrada progresivamente los lazos sociales, las formas de interacción colectiva y sentido de pertenencia. Las organizaciones del estado y gobernantes justifican su insuficiencia de capacidades para atender la desigualdad y la delincuencia, en la criminalización y segurización de la población más vulnerable, heredera de las desventajas acumuladas de raza y clase social; de tal forma, que los más pobres cada vez tienen menos alternativas e incentivos en su entorno, para insertarse funcionalmente en la sociedad.

Llevamos sexenios comprobando que la solución ante el aumento de la delincuencia no está en la seguridad pública y endurecimiento de las penas, sino en los lazos que la familia, la escuela y la comunidad forjan entre los sujetos y la sociedad. Estas instituciones son lugares clave en la formación y construcción de sentido de pertenencia, para que los ciudadanos puedan participar funcionalmente en la sociedad.

En este sentido, es pertinente hablar de la prevención temprana de la violencia y predelincuencia, ambas categorías apuntan hacia la necesidad de considerar la amalgama entre la violencia estructural y la violencia directa, las particularidades (causalidades y efectos) en los territorios y la prevención del delito como una forma estratégica de mediación en función del territorio y las violencias localizadas.

La especialización de la población, entendida como segregación y separación entre pobres, clases medias y ricos, así como en zonas de alto riesgo y bajo riesgo, tampoco ha solucionado las violencias, ni la delincuencia. Ya investigaciones sobre el tema han documentado que los infractores también viven en fraccionamientos y comunidades cerradas.

\section{Bibliografía}

Adame Cerón, M. Á. (2014). Violencias, bullying y juegos de la muerte. Ciudad de México, México: Ediciones Navarra.

Arendt, H. (2008). Sobre la violencia. Madrid, España: Alianza.

Azaola, E. (2008). Crimen, castigo y violencias en México. Ciudad de México, México: Facultad Latinoamericana de Ciencias Sociales (FLACSO) y Centro de Investigaciones y Estudios Superiores en Antropología Social (CIESAS).

Baños Nodedal y A. A. (2005). Antropología de la violencia. En C. Serrano Sánchez, P.O. Hernández Espinoza y F. Ortiz Pedraza (eds.), Estudios de Antropología Biológica (pp. 41-61). Ciudad de México, México: UNAM.

Barrera Méndez, J. A. (2010). El miedo colectivo: el paso de la experiencia individual a la experiencia colectiva. El Cotidiano, enero-febrero (159), 5-10. Recuperado de http://www.redalyc.org/pdf/325/32512747002.pdf 
Bufachi, V. (2015). Dos conceptos de violencia. En A. Aguirre, A. Nochebuena y M. Garcia Aguilar (eds.), Estudios para la no violencia I (pp. 129-147). Atizapán de Zaragoza, México: Afinita Editorial.

Carrizales, D. (20 junio, 2017). Otro motín en Topo Chico... ahora por el traslado de reos. El Universal. Recuperado de https://www.eluniversal.com.mx/articulo/estados/2017/06/20/otro-motin-en-topochico-ahora-por-el-traslado-de-reos

Casillas R., R. (2016). Violencia y migración en México. Una elaboración conceptual. En S.P. Izcara Palacios y K.L. Andrade Rubio (eds.), Migración indocumentada y trata de personas (pp. 17-71). Ciudad de México, México: Editorial Fontamara.

Castells, M. (2006). La era de la información. Fin del milenio, Volumen 3. Madrid, España: Alianza.

Cohen, A. (1979). Antropología Política. El análisis del simbolismo en las relaciones de poder (pp. 27-53). En J.R. Llovera (ed.), Antropología Política. Barcelona, España: Anagrama.

De Dios Palma, A. (7 julio, 2017). Deja 28 muertos riña en penal de Acapulco. El Universal. Recuperado de https://www.eluniversal.com.mx/articulo/estados/2017/07/7/masacran-28internos-en-el-penal-de-acapulco\#imagen-1

Díaz, G. L. (8 julio, 2017). Los Moreira, denunciados ante la Corte Penal Internacional. Proceso. Recuperado de http://www.proceso.com.mx/494156/los-moreiradenunciados-ante-la-corte-penal-internacional

Díaz-Salazar, R. (2011). Desigualdades internacionales. Barcelona, España: Icaria Editorial.

González Luna, F. (2018). Geografía de la violencia. Una aproximación conceptual al fundamento espacial de la violencia estructural, México: Universidad Nacional Autónoma de México.

Elster, J. (2007). La explicación del comportamiento social. Más tuercas y más tornillos para las ciencias sociales. Ciudad de México, México: Editorial Gedisa.

Encuesta Nacional de Victimización y Percepción sobre la Seguridad Pública (2017), INEGI, México. Recuperado de: http://www.beta.inegi.org.mx/proyectos/enchogares/regulares/envipe/2017/

Encuesta Nacional de Victimización y Percepción sobre la Seguridad Pública (2012), INEGI, México. Recuperado de: http://www.beta.inegi.org.mx/proyectos/enchogares/regulares/envipe/2012/

Farrington, D. P. (1999). Cambridge Study in Delinquent Development [Great Britain], 1961-1981. Recuperado de: https://library.carleton.ca/sites/default/files/find/data/surveys/pdf files/csdd-uk61-81-cbk.pdf

Ferrandiz Martín, F. y Feixa Pampols, C. (2004). Una mirada antropológica sobre las violencias. Alteridades, 14 (27), pp. 159-174.

Flores Contreras, E. (8 julio, 2017). Informe interno de Fiscalía revela 34 muertos y 32 heridos en el penal de Acapulco. Proceso. Recuperado de http://www.proceso.com.mx/494142/informe-interno-fiscalia-revela-34-muertos32-heridos-en-penal-acapulco

García Ramírez, S. (2017). La Constitución y el sistema penal: setenta y cinco años (1940-2015). En S. García Ramírez y O. Islas De González Mariscal (eds.) Evolución del sistema penal mexicano, Tres cuartos de siglo (pp. 3-30.). Ciudad de México, México: UNAM (Universidad Nacional Autónoma de México), INACIPE (Instituto Nacional de Ciencias Penales). Recuperado de https://archivos.juridicas.unam.mx/www/bjv/libros/10/4770/3.pdf

Gledhill, J. (2016). La nueva guerra contra los pobres. La proporción de inseguridad en Latinoamérica. Barcelona, España: Bellaterra.

Gledhill, J. (2000). El poder y sus disfraces. Barcelona, España: Bellaterra. 
González Antonio, H. (5 junio, 2017). Investigan balacera y fuga de 29 reos en el penal de Ciudad Victoria. Excelsior. Recuperado de http://www.excelsior.com.mx/nacional/2017/06/15/1170034

Izcara Palacios, S. P. y Andrade Rubio, K. L. (2016). Introducción. En S.P. Izcara Palacios y K.L. Andrade Rubio (eds.), Migración indocumentada y trata de personas (pp. 9-13). Ciudad de México, México: Editorial Fontamara.

Redacción Proceso (2 julio, 2017). Mancera alerta por la posible liberación de cuatro mil reos; pide a sociedad que se prepare. Proceso. Recuperado de http://www.proceso.com.mx/494052/mancera-alerta-por-la-posible-liberacion-decuatro-mil-reos-pide-a-sociedad-que-se-prepare

López, N., Kessler, G., Urresti, M., D’Alessandre, V., Sourrouille, F. y Caderosso M., (2008), La escuela y los adolescentes. Informe sobre tendencias sociales y educativas en América Latina 2008. International Institute for Educational Planning, UNESCO Sede Regional Buenos Aires y Organización de Estados Iberoamericanos para la Educación, la Ciencia y la Cultura (OEI), España. Recuperado de: www.oei.es/historico/pdfs/siteal2008.pdf/

Martínez, F. (2 junio, 2018). Hay 37 mil 435 desaparecidos, informa la SG. La Jornada. Recuperado de https://www.jornada.com.mx/ultimas/politica/2018/06/02/hay-37mil-435-desaparecidos-informa-la-sg-9863.html

Martínez-Solares, V. y Aguilar Sánchez, O. (2017). Prevención de la violencia y el delito en 75 años de análisis de la evolución teórica. En S. García Ramírez y O. Islas de González Mariscal (eds.), Evolución del sistema penal mexicano, Tres cuartos de siglo (pp. 3-30). Ciudad de México, México: UNAM (Universidad Nacional Autónoma de México), INACIPE (Instituto Nacional de Ciencias $\begin{array}{lll}\text { Penales), } & \text { México. } & \text { Recuperado } \\ \text { https://archivos.juridicas.unam.mx/www/bjv/libros/10/4770/13.pdf }\end{array}$

Molina Rodríguez, D. (2012). VI. Contexto y conducta violenta. Los adolescentes en conflicto con la Ley penal. En I.T. Guevara Martínez y A. Mojardín Heráldez, La violencia en Sinaloa. Materiales para una psicología cultural (pp. 137-158). Culiacán Rosales, México: Universidad Autónoma de Sinaloa.

OCDE (2018). Education at a Glance 2018. OECD Indicators, París: OECD Piblishing. Recuperado de https://www.oecd-ilibrary.org/docserver/eag-2018en.pdf?expires $=1568092035 \&$ id=id\&accname=quest\&checksum=53A47E797BF A8573BDA6207CC508AFA9

Pérez Islas, J. A. (2009). Las cuatro transformaciones históricas de la condición juvenil. En M. Urteaga Castro-Pozo (coord.), Juventudes, culturas, identidades y tribus juveniles en el México contemporáneo. Suplemento de Diario de Campo (56), pp. 29-35.

Programa de las Naciones Unidas para el Desarrollo (2016), Informe sobre Desarrollo Humano. Recuperado de http://www.mx.undp.org/content/dam/mexico/docs/Publicaciones/Publicaciones ReduccionPobreza/InformesDesarrolloHumano/idhmovilidadsocial2016/PNUD\% 20IDH2016.pdf (fecha de consulta: 23 de mayo de 2017).

Recasens Salvo, A. (2005-2006). Aproximaciones antropológicas al fenómeno de la violencia, Revista de Antropología, 18, pp. 31-58. doi: 10.5354/07191472.2012.17969

Redacción Proceso (2 julio, 2017). Mancera alerta por la posible liberación de cuatro mil reos; pide a sociedad que se prepare. Proceso. Recuperado de http://www.proceso.com.mx/494052/mancera-alerta-por-la-posible-liberacion-decuatro-mil-reos-pide-a-sociedad-que-se-prepare

Reguillo, R. (2009). Jóvenes imaginados: la disputa por la representación (contra la esencialización). En M. Urteaga Castro-Pozo (coord.), Juventudes, culturas, identidades y tribus juveniles en el México contemporáneo. Suplemento de Diario de Campo, octubre-diciembre, 56, pp. 41-48. 
Reguillo, R. (2008). Los dialectos de la violencia. En N. López, G. Kessler, M. Urresti, V. D'Alessandre, F. Sourrouille y M. Caderosso, La escuela y los adolescentes. Informe sobre tendencias sociales y educativas en América Latina 2008 (pp. 138139). Buenos Aires, Argentina: International Institute for Educational Planning, UNESCO Sede Regional Buenos Aires y Organización de Estados Iberoamericanos para la Educación, la Ciencia y la Cultura (OEI), España.

Reguillo, R. (2003). Las culturas juveniles: un campo de estudio; breve agenda para la discusión. Revista Brasileira de Educação, 23, pp. 103-118. doi: 10.1590/S1413-24782003000200008

Reguillo, R. (2000). Emergencia de culturas juveniles. Estrategias del desencanto. Ciudad de México. México: Grupo Editorial Norma.

Sandoval García, C. (2015). No más muros: exclusión y migración forzada en Centroamérica. Costa Rica: Universidad de Costa Rica (UCR).

Saraví, A. G. (2015). Juventudes fragmentadas. Socialización, clase y cultura en la construcción de la desigualdad. Ciudad de México, México: Facultad Latinoamericana de Ciencias Sociales (FLACSO) y Centro de Investigaciones y Estudios Superiores en Antropología Social (CIESAS).

Tortosa, J. M. (2008). La amenaza definitiva a la paz: las armas nucleares. En N. Arteaga Botello, J.G. Arzate Salgado, J.A. Arzuaga Magnoni y G. Díaz Pérez, Violencia, ciudadanía y desarrollo (pp. 15-40). Ciudad de México, México: Miguel Ángel Porrúa Editorial.

Urteaga Castro-Pozo, M. (2009). Juventud y antropología: una exploración de los clásicos en Juventudes, culturas, identidades y tribus en el México contemporáneo. Suplemento de Diario de Campo, octubre-diciembre, 56, pp. 1328.

Useche Aldana, O. (2008). Miedo, seguridad y resistencias: el miedo como articulación política de la negatividad. Polis, Revista Latinoamericana, 19. Recuperado de: https://journals.openedition.org/polis/3893\#bibliography

Valdez, M. (2009). Jóvenes y datos, Panorama de la desigualdad. En: URTEAGA Castro-Pozo, M., Juventudes, culturas, identidades y tribus juveniles en el México contemporáneo. Suplemento de Diario de Campo, octubre-diciembre (56), pp. 3739.

Valenzuela Aguilera, A. (2016). La construcción espacial del miedo. Ciudad de México, México: Juan Pablos Editorial y Universidad Autónoma de Morelos.

Weber, M. (1919). El político $y$ el científico. Recuperado de: http://www.hacer.org/pdf/WEBER.pdf 